\title{
Low Temperature Curable Polyaniline/Bio-based polybenzoxazine Coated Cotton Fabric with Superior UV shielding and Oil-water Separation behaviours
}

Prabunathan $P$

PSG Institute of Technology and Applied Research

M. Alagar ( $\square$ mkalagar@yahoo.com )

PSG Institute of Technology and Applied Research https://orcid.org/0000-0002-1661-5726

\section{Research Article}

Keywords: Cardanol benzoxazines, polyaniline, low temperature curing, cotton fabric, UV-shielding, superhydrophobic behaviour

Posted Date: March 30th, 2021

DOl: https://doi.org/10.21203/rs.3.rs-363856/v1

License: (c) (1) This work is licensed under a Creative Commons Attribution 4.0 International License.

Read Full License 


\section{Abstract}

The present work detailsabout the low temperature curingbehaviour of bio-benzoxazine (C-ddm) prepared using cardanol and diaminodiphenylmethane ( $\mathrm{ddm}$ )in the presence of polyaniline (PANI). Interestingly, it was found that the curing temperature $\left(T_{p}\right)$ of the benzoxazine monomer (C-ddm) has significantly reduced to $227^{\circ} \mathrm{C}$ from $271^{\circ} \mathrm{C}$ with the incorporation of $2 \mathrm{wt} \%$ of PANI. The plausible curing mechanism of benzoxazine ring catalysed by PANI was also discussed. Further, the resulted PANI/poly(C-ddm) matrices possessa marginally improvedvalues of glass transisition temperature and char yield. Further, PANI/poly(C-ddm) coated cotton fabric was studied for its UV shielding and surface properties. Furthermore, the UV shielding and surface behaviours of PANI/poly(C-ddm) coated cotton fabrics were explored. The PANI/poly(C-ddm) coated cotton fabric delivered UPF rating as high as $50+$ and water contact angle value of $162^{\circ}$. In addition, the PANI/poly(C-ddm) coated cotton fabric wasverified for its oilwater separation behavior. It was observed that the PANI/poly (C-ddm) coated cotton fabric offered $97.5 \%$ separation efficiency with enhanced flux value of about $6450 \mathrm{~L} / \mathrm{m}^{2} \mathrm{~h}$ flux.Thus, the obtained results suggest that the PANI/poly(C-ddm) can be used some of the industrial and environmental surface protection applications.

\section{Introduction:}

Polybenzoxazine, a novel class of thermoset resin comparatively owns an attractive characteristics such as catalyst-free polymerization, zero shrinkage, superior thermo-mechanical properties, low dielectric constant, and low surface free energy [1-7]. In addition, the intrinsic chemical compatibility with other traditional polymers is another valuable behaviour of benzoxazines[8-13]. Hence, benzoxazine resins are extensively employed to enhance specific properties of other polymeric materials either through blending/hybridization or copolymerization. Very recently, bio-based benzoxazines are being explored from both industrial and academic perceptives in order to meet the growing demand of petro-chemical feedstocks [14-17]. Meantime, bisphenol-A was seriously studied for its toxic nature, which is a prime petro-chemical feedstock used for polymeric precursors viz., epoxies, polycarbonates, polyarylates, etc[18-21]. This motivates the researchers to explore the novel synthetic and bio-based phenolic precursors instead of bisphenol-A[22-26].

In this context, bio-based benzoxazines have been synthesized from different bio-phenolic derivatives such as, cardanol, diphenolic acid, vanillin, and eugenol. Cardanol derived benzoxazine is one among the bio based polymer that substitutes an environmentally hazardous petroleum phenolic derivatives like bisphenol-A, bisphenol-F in recent day's[27-31]. Cardanol-benzoxazines was first prepared Cao et al[32]followed by various groups have developed skeletally modified monomers[23, 33-35]. In spite of environmental friendly nature, cardanol benzoxazines demand comparatively even high temperature for curing than that of conventional ones[36].In general, catalyst usage can considerably reduce the curing temperature of benzoxazines[37-39]Therefore continuous efforts are under progress to reduce the curing temperature of cardanol benzoxazines using catalysts[33, 40]. Previously our group have used tertiary amine as catalyst[41]. Very recently, Polypyrrole (PPy) catalyzed curing of benzoxazine at low 
temperature was explored[42]. Commercially available primary amines[38] and amine-capped aniline trimer (quinoid) are chosen as catalyst to cure benzoxazines[43] by different groups. These results suggest that amine group could impart low temperature cure for benzoxazines through their catalytic role.

However, no significant attention has been focused on the role of polyaniline (PANI) as catalyst to cure benzoxazines. PANI is well known as conductive polymer with conjugated six membered rings holding a secondary amine (-NH-R-) and imine (-R-N = C-) linkages. Because of its easy synthesis, high conductivity, excellent stability, low-cost and high yield, great attention has been focused on the PANI towards different applications. For the first time, it has been chosen to catalyse the curing process of benzoxazine monomers. It is expected that, similar to amine and amine capped quinoid moiety, PANI could also impart ring opening at low temperature with lower activation energy. Hence, in the present work the curing and thermal properties ofPANI/poly(C-ddm)has been studied. In addition,thevarying weight percentages ofPANI incorporated cardanol-benzoxazine(C-ddm) wascoated over cotton fabric and studied for their UV shielding and oil-water separation behaviour in detail. The data resulted from different studies are discussed and reported.

\section{Experimental:}

Materials and methods:

Cardanol was purchased from Satya Cashew Products, Chennai. Tamilnadu.Aniline, diaminodiphenylmethane (DDM) and formaldehyde were obtained from SRL Pvt. Ltd. India.Anhydrous sodium sulphate, ethanol, tetrahydrofuran (THF) and ethylacetate were obtained from Loba chemicals, India. Cotton fabric was procured from textile industry in Erode, Tamilnadu, India.

Preparation of Polyaniline (PANI):

Conductive polyaniline was prepared as per the reported literature[44]. $1 \mathrm{~mL}$ of freshly distilled aniline monomer was dissolved in $50 \mathrm{~mL}$ of $1 \mathrm{M} \mathrm{HCl}$ and subjected to sonication for 30 minutes. Subsequently, the homogeneous solution ofammonium per sulphate dissolved in $50 \mathrm{~mL}$ of hydrochloric acid $(1 \mathrm{M})$ wasadded slowly and stirred for another $5 \mathrm{~h}$ at $0-5^{\circ} \mathrm{C}$ in an ice bath. Then, the resulted green product was washed several times with $1 \mathrm{M} \mathrm{HCl}$ and dried in a hot air oven at $60^{\circ} \mathrm{C}$.

Preparation of PANI/poly(C-ddm) matrices:

Cardanol and DDM benzoxazine (C-ddm) monomer was synthesized through Mannich reaction via a solvent-less method using stoichiometric quantities of (2:1:4) of cardanol, DDM, and formaldehyde as per the reported procedure[33]. Different weight percentages of PANI $(0.5,1.0,1.5$, and $2.0 \mathrm{wt} \%)$ were added to solution containing $5.0 \mathrm{~g}$ of monomer (C-ddm) dissolved in $15 \mathrm{ml}$ of THF. The resulting mixtures was stirred separately for $12 \mathrm{~h}$ at room temperature and then poured into respective silane-coated glass plates. After evaporation of the solvent at room temperature for $8 \mathrm{~h}$, the polymerization was initiated via 
stepwise thermal curing $\left(120^{\circ} \mathrm{C}, 160^{\circ} \mathrm{C}, 200^{\circ} \mathrm{C}\right.$, and $240{ }^{\circ} \mathrm{C}$ for $2 \mathrm{~h}$ respectively) to obtain the corresponding PANI/poly(C-ddm) matrices.

Preparation of PANI, poly(C-ddm) andPANI/poly(C-ddm) coated cotton fabric:

Exactly $1 \mathrm{~g}$ of the C-ddm monomer was allowed to dissolve in $10 \mathrm{~mL}$ of THF. To the prepared solution, appropriate amount of PANI were added and sonicated for $1 \mathrm{~h}$. Subsequently, the pristine cotton was soaked and left for 20 minutes and then dried at $60^{\circ} \mathrm{C}$ for $2 \mathrm{~h}$. After complete removal of solvent, the fabric was cured at $180^{\circ} \mathrm{C}$ for 5 minutes. For comparison, poly(C-ddm) and PANI were separately coated over cotton fabrics. The coating of PANI over cotton fabric was carried out during the preparation of PANI itself. While preparing PANI, the cotton fabric was soaked with aniline and sonicated in $\mathrm{HCl}$ medium before to the addition of oxidant APS. All other procedures are similar to preparation of PANI. The resulted $\mathrm{PANI} /$ cotton fabrics show dark green color as a result of coating of polyaniline network, which was washed several times with $1 \mathrm{M} \mathrm{HCl}$ and dried in a hot air oven at $60^{\circ} \mathrm{C}$.

Characterization:

FT-IR spectra were recorded on a Perkin Elmer 6X FT-IR spectrometer using $\mathrm{KBr}$ as reference. DSC measurements were recorded using Hitachi DSC7020 under $\mathrm{N}_{2}$ purge $\left(60 \mathrm{~mL} \mathrm{~min}^{-1}\right)$ at a scanning rate of $10{ }^{\circ} \mathrm{C} \mathrm{min}^{-1}$.Thermogravimetric analysis (TGA) was performed on a Netzsch STA 409 thermo gravimetric analyzer calibrated with calcium oxalate and aluminium. About $50 \mathrm{mg}$ of the samples was heated under a nitrogen atmosphere at a heating rate of $10{ }^{\circ} \mathrm{C} \mathrm{min}-1$. The morphology of the PANI/poly(C-ddm), PANI, poly (C-ddm) and PANI/poly(C-ddm)coatedcotton fabrics were identified usingZeiss Sigma Field Emission Scanning Electron Microscope (FESEM). The water contact angle measurements of the PANI, poly(C-dm) and PANI/poly(C-ddm) coated cotton fabrics were conducted on a Data physics instrument (OCA 15, Germany) using a water drop $(V=10 \mu \mathrm{L})$ gently placed on the surface of the sample.UV Transmittance Analyser was used to determine UPF of the cotton fabrics in accordance with AS/NZS 4399:1996 standard. Oil-water separation studies was performed using oil-water mixture under gravitational force (i.e., without any force). The oil-water mixture was prepared using equal amount of water and petrol. Further, dichloromethane (DCM) was added to move the petrol layer down and water was once again addedto maintain the volume ratio equivalent to that of DCM. The separation efficiency and flux behaviour of the PANI/poly(C-ddm) coated cotton was calculated using equations 1 and 2 respectively.

$$
\begin{aligned}
& \text { Separation efficiency }(\%)=\frac{\text { Volume of the oil after separation }}{\text { Volume of the oil before separation }} \times 100 \\
& \qquad \text { Flux }(\mathrm{L} / \mathrm{m} 2 \mathrm{~h})=\frac{\text { Volume of the permeated oil }}{\text { Area of the fabric X time for separation }} \ldots \ldots \ldots \ldots
\end{aligned}
$$

\section{Results And Discussion:}


Spectral analysis of C-ddm:

Figure $1 \mathrm{a}$.and $1 \mathrm{~b}$ illustrates the ${ }^{1} \mathrm{H}$-NMR and ${ }^{13} \mathrm{C}$-NMR spectra of the C-ddm monomer. The two singlets from the methylene protons of oxazine rings show signals at $\delta 4.5$ and $\delta 5.5 \mathrm{ppm}$ in ${ }^{1} \mathrm{H}-\mathrm{NMR}$ spectrum (Figure 1a). The terminal methyl protons of cardanol moiety appeared at $\delta 0.9 \mathrm{ppm}$. The signal at $\delta 3.9$ ppm (Figure 1a) corresponds to the signal of methylene protons of ddm $\left(\mathrm{Ar}^{-} \mathrm{CH}_{2}-\mathrm{Ar}\right)$. The major signals appeared between $\delta 1.0$ and $2.0 \mathrm{ppm}$ correspond to aliphatic chain protons of cardanol moiety. The multiplet signals appeared around $\delta 6.5-7.2$ correspond to the aryl ring protons. Figure $1 \mathrm{~b}$ illustrates the ${ }^{13} \mathrm{C}$-NMR spectrum of C-dda monomer. Two signals appeared at $\delta 50$ and $\delta 80 \mathrm{ppm}$ (Figure 1b) were correspond to the respective methylene carbons namely $\left(-\mathrm{N}^{-} \mathrm{CH}_{2}-\mathrm{Ar}\right)$ and $\left(-\mathrm{N}-\mathrm{CH}_{2}-\mathrm{O}-\right)$ of benzoxazine rings respectively. The quaternary carbon of the benzoxazine ring adjacent to oxygen atom appeared in the deshielding region at $\delta 158 \mathrm{ppm}$ (Figure 1b), whereas the quaternary carbon of ddm ring adjacent to nitrogen atom appeared at $\delta 148 \mathrm{ppm}$ (Figure 1b).The methylene carbon bridging two aryl rings of ddm shows signal at $\delta 40 \mathrm{ppm}$ (Figure 1b).Further, the multiplet from $\delta 115$ to $135 \mathrm{ppm}$ corresponds to the aromatic carbon signals of benzene ring present in both cardanol and ddm. Two strong signals appeared at $\delta 122$ and 126 were correspond to the unsaturated carbon and a sharp singlet signal at $\delta 12 \mathrm{ppm}$ corresponds to the terminal methyl carbon of the aliphatic side chain of cardanol. Besides, the other aliphatic carbon present in the side chain of the cardanol contributes for the multiplet signals observed from $\delta 15$ to $40 \mathrm{ppm}$. The observed results are in accordance with those of reported literature[45, 46].

Curing behaviour of C-ddm and PANI/C-ddm:

Before ascertaining the thermal and coating behaviour of PANI/poly (C-ddm) it is essential to study the curing nature of C-ddm monomer in the presence of PANI. The general ring opening polymerization of benzoxazine monomer is presented in Scheme 1, which normally occursat high temperature. Similarly, the curing temperature $\left(T_{p}\right)$ of $\mathrm{C}$-ddm monomer was observed at $271^{\circ} \mathrm{C}$ (Figure 2). However, in the presence of PANI (Figure 2)the polymerization occurs at $\mathrm{T}_{\mathrm{p}}$ tends to decreases. For example, in the presence of 0.5 and $1.0 \mathrm{wt} \%$ of PANI the $\mathrm{T}_{\mathrm{p}}$ values are observed to be 267 and $258^{\circ} \mathrm{C}$. The $\mathrm{T}_{\mathrm{p}}$ value of Cddm further decreases and reaches the $227^{\circ} \mathrm{C}$ (Figure 2)as the lowest $T_{p}$ in the presence of $2 \mathrm{wt}$. \% of PANI. Addition of succeeding amount of PANI $(3,4$ and $5 \mathrm{wt} \%)$ also results in $\mathrm{T}_{\mathrm{p}}$ value similar to that of 2 $w t \%$ PANI. This phenomenon inference that the addition of PANI beyond $2 \mathrm{wt}$. \% has no significant contribution towards reduction in $T_{p}$. The plausible mechanism corresponds to the curing of C-ddm with lower energy pathway in the presence of PANI was presented in Scheme 2. Similar to other primary and secondary amines, the PANI with continuous benzene ring linked through a secondary aminesactas a catalyst. The secondary amines nitrogen atoms of polyaniline donates their lone pair of electron to initiate the polymerization through nucleophilic attack and favours rapid formation of zwitter ion intermediate (Scheme 1), which in turn proceeds with proton transfer and assist the polymerization[42]. In the present work, curing temperature of C-ddm in the presence of $2 \mathrm{wt}$. \% PANI was observed to be as low as $\mathrm{Tp}=227^{\circ} \mathrm{C}$, whichis considerablysignificant in comparison to those of other amine and hydroxyl catalysts[39-41,43,47]In order to support the effectiveness of PANI, the curing behaviour of C-ddm in the 
presence of aniline as equivalent to that of PANI was added and verified. The observed DSC thermogram is illustrated in Figure S2. The Tp value observed for C-ddm in the presence of aniline is about $251^{\circ} \mathrm{C}$, which is not as low as PANI.

Spectral analysis of PANI, poly(C-ddm) and PANI/ poly(C-ddm) :

Figure 3represents the FT-IR spectra of PANI, neat poly(C-ddm) and PANI/poly(C-ddm). Generally the benzoxazine moiety shows vibration band around $940 \mathrm{~cm}^{-1}$. However, after thermal curing thepeak at 940 $\mathrm{cm}^{-1}$ disappears, which infers the ring opening polymerizationof benzoxazine monomer. Thus, the absence of peak at $940 \mathrm{~cm}^{-1}$ in Figure 3 confirms the occurrence of ring opening polymerization of oxazine rings and thereby confirms the formation of poly(C-ddm). Further, the appearance of peaks at $1613 \mathrm{~cm}^{-1}$ and $1502 \mathrm{~cm}^{-1}$ also ascertain the ring opening polymerization, which are corresponding to the vibration bands of trisubstituted and tetrasubstituted benzene rings of poly (C-ddm) respectively. These phenomenon are also observed for PANI/poly $(\mathrm{C}-\mathrm{ddm})$ matrices $[48,49]$ in Figure 3 , suggesting that the presence of PANI doesn't disturb the curing nature of C-ddm. In addition, the presence of PANI in the PANI/poly(C-ddm) matrices are confirmed through the appearance of bands at 1566 and $1472 \mathrm{~cm}^{-1}$, which are corresponding to the $\mathrm{C}=\mathrm{C}$ stretching vibration of the quinonoid and benzenoid rings respectively. In addition, the peak appeared at $1306 \mathrm{~cm}^{-1}$ is attributed to the $\mathrm{C}-\mathrm{N}$ stretching vibration[5052]. The FTIR spectrum of PANI (Figure 3) also shows a similar vibration band representing the quinonoid and benzenoid rings, which confirms the presence of PANI in poly (C-ddm) matrices. The shifting of $\mathrm{N}-\mathrm{H}$ band to lower wavenumber suggeststhe existence of inter molecular hydrogen bonding between PANI and poly (C-ddm) matrices.

Morphology of poly(C-ddm) and PANI/ poly(C-ddm)

The cross sectional morphology of theneat poly(C-ddm) and PANI/poly(C-ddm) matrices were investigated using FE-SEM analysis. The FESEM image of neat poly(C-ddm) presented in Figure 4a shows smooth surface corresponding to the existence of homogenous phase of cardanol polybenzoxazine. On the other hand, the morphology of PANI/poly $(\mathrm{C}-\mathrm{ddm})$ matrices shown in Figure $4 \mathrm{~b}$ and $4 \mathrm{c}$, possess rough surfaces. The appearances of rough and heterogeneous phases in the matrices confirm the presence of PANI as intercalated network. It is important to note that two different phases are observed in the SEM images with higher concentration of PANI, which are highlighted through a circle. The irregular module corresponds to the intercalated phase of PANI, whereas, the continuous module represents the phases of poly (C-ddm). Comparably, the Figure $4 \mathrm{e}$, provides more irregular intercalated phase, which consequently results low temperature curing to benzoxazines.

Thermal properties:

Table 1. Thermal Properties of neat poly(C-ddm) and PANI/poly(C-ddm) 


\begin{tabular}{|c|c|c|c|c|c|c|}
\hline \multirow[t]{2}{*}{ Sample Code } & \multirow[t]{2}{*}{$\begin{array}{l}\mathrm{T}_{\mathrm{p}} \\
\left({ }^{\mathrm{O}} \mathrm{C}\right)\end{array}$} & \multicolumn{3}{|c|}{$\begin{array}{l}\text { Temperature at characteristic } \\
\text { weight loss }\left({ }^{\circ} \mathrm{C}\right)\end{array}$} & \multirow{2}{*}{$\begin{array}{l}\text { Char yield } \\
\text { at } \\
750{ }^{\circ} \mathrm{C}(\%)\end{array}$} & \multirow[t]{2}{*}{$\begin{array}{l}\mathrm{T}_{\mathrm{g}} \\
\left({ }^{\circ} \mathrm{C}\right)\end{array}$} \\
\hline & & $20 \%$ & $40 \%$ & $60 \%$ & & \\
\hline poly(C-ddm) & 272 & 332 & 407 & 553 & 3.4 & 139.4 \\
\hline 0.5 wt\% PANI/poly(C-ddm) & 267 & 336 & 427 & 557 & 3.5 & 143.1 \\
\hline 1.0wt \% PANI/poly(C-ddm) & 259 & 339 & 441 & 568 & 4.7 & 143.5 \\
\hline 1.5 wt\% PANI/poly(C-ddm) & 243 & 342 & 450 & 574 & 5.6 & 143.4 \\
\hline 2.0 wt\% PANI/poly(C-ddm) & 227 & 399 & 464 & 608 & 10.8 & 143.5 \\
\hline
\end{tabular}

In order to ascertain the thermal stability, thermal behaviour of neat poly(C-ddm) and PANI/poly(C-ddm) matrices were studied using thermo-gravimetric analysis. The resulted thermo-grams are presented in Figure 5 and the temperatures corresponding to different percentages of degradation are also given in Table 1. It was noticed that the PANI incorporated cardanol polybenzoxazines possesses an appreciable improvement in thermal stability. Under the thermal condition, the degradation of both neat poly(C-ddm) and PANI/poly(C-ddm) matrices occurs in two steps. Initial degradation occurs below $350^{\circ} \mathrm{C}$ followed by second stage degradation after $550^{\circ} \mathrm{C}$. However, with respect to the PANI, the thermal degradation is prolonged to high temperatures. For example, $20 \%$ weight loss of $2.0 \mathrm{wt} \% \mathrm{PANI} /$ poly(C-ddm) was found at $399^{\circ} \mathrm{C}$, whereas that of neat poly $(\mathrm{C}-\mathrm{ddm})$ begins earlier at $332^{\circ} \mathrm{C}$. This phenomenon's may be explained due to the presence of PANI network possessing continuous aromatic backbone (quinonoid and benzenoid rings) and hetero linkage $(\mathrm{N}-\mathrm{H})$, that provides stability and sustainability to the poly (C$\mathrm{ddm}$ ) against thermal energy[53,54]. Consequently, the final residual char yields (Table 1 ) of the PANI/poly(C-ddm) were increased as theconcentration of the PANI increases. Thus, $2.0 \mathrm{wt} \% \mathrm{PANI} /$ poly (C$\mathrm{ddm}$ ) matrices offers highestchar residue of $10.8 \%$ at $750^{\circ} \mathrm{C}$, when compared to that of neat poly(C$\mathrm{ddm}$ ), which shows only $3.4 \%$. This confirms the presence of intercalated network of PANI within the poly(C-ddm)and provides appreciable thermal stability.

Further, the DSC thermograms of neat poly(C-ddm) and PANI/poly(C-ddm) matrices were analysed in order to ascertain their molecular chain mobility with respect to temperature [(glass transition temperature $\left(T_{g}\right)$ ]. Figure 6 presents the DSC profile of poly $(C-d d m)$ and PANI/poly $(C-d d m)$. The poly $(C-$ $\mathrm{ddm}$ ) shows the value of $\mathrm{Tg}$ about $136.4^{\circ} \mathrm{C}$. The $\mathrm{Tg}$ value of the PANI/poly(C-ddm) has no significant shift. The addition of $2.0 \mathrm{wt}$. \% PANI, only Tg value as high as $143.5^{\circ} \mathrm{C}$ (Table 1 ). This phenomenon could be attributed to the (i) inherent flexible network of PANI as well as (ii) intercalation of PANI in between the polybenzoxazine matrices [55].In general, polybenzoxazine are widely used as coating material to avoid corrosion due to their superior hydrophobicity $[56,57]$. Hence, in the present work to verify the real time utility of PANI/poly(C-ddm) the samples were coated over cotton fabric and subsequently studied for UV shielding and surface properties along with oil-water separation behaviour. Hence, the $2.0 \mathrm{wt} \%$ 
PANI/poly(C-ddm) was used as coating material for cotton fabric and studied for its surface properties and radiation shielding behavior in comparison with neat cotton, $\mathrm{PANI}$, and poly (C-ddm) coated cotton.

Spectral and morphology of treated cotton fabrics:

Figure. 7 illustrates the FTIR spectra of the PANI, poly(c-ddm) and PANI/poly(C-ddm) coated cotton fabric in comparison with pristine cotton. In case of pristine cotton, the presence of polar carboxylic acid functional group and C-O-C linkage on the surface gives rise to vibration bands at $1712 \mathrm{~cm}^{-1}$ and 1246 $\mathrm{cm}^{-1}$ respectively. Since the fabric was treated with sodium hydroxide, the primary hydroxyl groups might have been oxidized to the carboxylic group[58]. After coating with PANI, due to the presence of only $2 \mathrm{wt}$ $\%$ coating, the respective bands corresponding to quininoid and benzenoid rings of polyaniline usually occurred at 1571 and $1476 \mathrm{~cm}^{-1}$ shows very weak signals. On the other hand, after coating with poly(C$\mathrm{ddm}$ ), the fabrics no distinct peaks for benzoxazines, which suggest that the ring-opening reactions of oxazine groups [15]. However, the peaks observed at $2917 \mathrm{~cm}^{-1}$ and $2844 \mathrm{~cm}^{-1}$ correspond to the asymmetric and symmetric stretching vibrations of a methylene group $\left(-\mathrm{CH}_{2}-\right)$ respectively of long alkyl side chains of cardanol moiety [31].

The morphology of cotton fabrics coated with poly(C-ddm), PANI and PANI/Poly(C-ddm) obtained from FE-SEM are compared with that of pristine fabric and the images are presented in Figure 8. The pristine fabric delivers smooth surface of cellulose fibrous before coating (Figure 8a-b). After coating the fabric shows rough surfaces due to the presence of supramolecular assembly of both poly(C-ddm) and PANI. Figure 8c-d shows the presence of new fibril morphology at the interfaces of warp and weft cellulose fibers, which confirms the coating of poly (C-ddm) over cotton fabric. Figure 8e-f shows the morphology of PANI coated fabric with uniform rough texture, which is due to nucleation and growth of conductive PANI layer. PANI/Poly(C-ddm) coated cotton fabrics contributes to both rough and fibril morphology [Figure $8(g-h)]$. The formation of hierarchically rough structured surface is highly desirable to enhance the water repelling behavior[26]. Thus, the rough surfaces formation aided by the coating of PANI/Poly(C-ddm) could create hydrophobic behavior of cotton fabric.

\section{UV Shielding property:}

Table 2 UPF profile of cotton fabrics.

\begin{tabular}{|llllll|}
\hline Sample & \multicolumn{2}{l}{ Transmittance (\%) } & Mean UPF & STD & UPF rating \\
\cline { 2 - 5 } & UVA & UVB & & & \\
\hline Pristine cotton fabric & 12.7 & 8.35 & 10.90 & 0.26 & 10 \\
\hline PANI/ cotton fabric & 4.41 & 4.40 & 22.72 & 1.06 & 20 \\
\hline Poly(C-ddm) & 0.07 & 0.05 & 1966.00 & 19.9 & $50+$ \\
\hline Poly(C-ddm)/PANI/cotton fabric & 0.05 & 0.05 & 2000.00 & 0.00 & $50+$ \\
\hline
\end{tabular}


The UV-visible transmittance spectra of pristine cotton, poly(C-ddm)/cotton PANI/cotton and PANI/Poly(C-ddm)/cotton fabrics are presented in Figure 9. The mean UPF values and UPF rating observed are also presented in Table 2. The UPF value (10.98) of pristine cotton presented in Table 2 and UV transmittance spectra (Figure 9) possesses the poor UV shielding behavior. However, after coating with PANI and poly(C-ddm) over the cotton fabrics, the UV shielding behavior was enhanced to an appreciable extent(Table2). Thus, the UPF values of PANI and poly(C-ddm) coated cotton fabrics are observed to be 22.7 and 1966 respectively. Further, the cotton fabric with both PANI and poly(C-ddm) delivers UPF value as 2000. The UPF value of poly(C-ddm)/cotton shows about an increase of 179 fold, whereas that of poly(C-ddm)/PANI/cotton shows an enhancement of about 183 fold. These phenomenon suggest that the polybenzoxazines layer present over the cellulosic fiber render complete UV protection. In addition to superhydrophobicity, the synergistic effect contributed by both PANI and poly(C$\mathrm{ddm}$ ) also provides constant protection for both UV-A and UV-B regions (Figure 9). It was well known that the PANI and polybenzoxazines are stable against UV radiations. The presence of three dimensional poly(C-ddm) matrices with continuous carbon network protects the fabric cellulose structure from UV radiations. In addition, the quinonoid and benzenoid rings of PANI also possessthe strong UV absorption behavior due to their $\mathrm{C}=\mathrm{C}$ skeleton and thereby provides the efficient UV shielding effect. It is reported that the energy of $\mathrm{C}=\mathrm{C}$ bonds is about $335 \mathrm{~kJ}$ which is approximately equal to the energy of UV photons[58]. Thus, synergistic effect of both poly (C-ddm) and polyaniline contributes to the UV shielding behavior, which are in equivalent to those of high cost graphene, metal oxide coated cotton fabric[59-61].

Water contact angle:

The values of water contact angle (WCA) of the pristine cotton, poly(C-ddm)/cotton PANI/cotton and $\mathrm{PANI} /$ poly $(\mathrm{C}-\mathrm{ddm}) /$ cotton fabrics are presented in Figure 10. The WCA of pristine fabric, poly(C$\mathrm{ddm}) /$ cotton, PANI/cotton and PANI/Poly $(\mathrm{C}-\mathrm{ddm}) /$ cotton fabrics are $0^{\circ}, 132^{\circ}, 124^{\circ}$, and $162^{\circ}$ respectively. This result infers that the cotton fabrics coated with PANI/poly(C-ddm) contributes to enhanced superhydrophobic behaviour due to the synergistic effect. It is well known that the aliphatic chain moiety could favour hydrophobic behaviour due to their non-polar nature[62]. As discussed from the SEM, the PANI/poly(C-ddm) coated fabric surfaces possesses protuberance and air beneath textured surfaces and in turn stack the water droplet to be sited on the top without contacting the fabric surface[63]. Thus, the reduced interfacial interaction creates the state of Cassie-Baxter attraction between the fabric and water surface and delivers enhanced values of contact angle.

\section{Oil-water separation behaviour of PANI/poly(C-ddm)/cotton:}

Further, to evaluate the real time utility of PANI/poly(C-ddm)/cotton fabricwas used to separate oil and water. Figure 10a-d illustrates the petrol-water separation behaviour using PANI/poly(C-ddm)/cotton fabrics as membrane. Figure 11a presents the prepared petrol-water mixture, in which due to low density the petrol layer exist above the water layer. In order to bring it down and make contact with the PANI/poly(C-ddm)/cotton fabrics DCM was added. After the addition of DCM, the petrol layer moves down and exist in the bottom of water layer (Figure 11b). Further, upon transferring the petrol-water 
mixture in DCM to the separating flask (Figure 11c), the petrol dissolved in DCM penetrates through the PANI/poly(C-ddm)/cotton fabrics immediately and leaving behind the water layer. Finally, Figure 11d illustrates separated layers water over the fabric and petrol in DCM in collection flask kept at the bottom. This phenomenon demonstrates the superhydrophobic and oleophilicity nature of PANI/poly(C$\mathrm{ddm}$ )/cotton fabric. Further, the separation efficiency and flux behavior of the PANI/poly(C-ddm)/cotton fabrics for subsequent 10 cycles were evaluated using equations 1 and 2 . The resulted separation efficiency and flux values are presented in Figure. 12a-b. The values of separation efficiency and flux were observed to be about 97.5 and $6425 \mathrm{~L} / \mathrm{m}^{2} / \mathrm{h}$ respectively.

\section{Conclusion}

In the present work, an attempt has been made to assess the thermal and surface properties of polyaniline (PANI) incorporated cardanol-diaminodiphenylmethane based polybenzoxazine [poly(c-ddm)] materials. The curing process of cardanol based benzoxazine was reduced to low temperature 227 ${ }^{\circ} \mathrm{Cfrom} 271{ }^{\circ} \mathrm{C}$, with the incorporation of $2 \mathrm{wt} \%$ PANI. The curing mechanism with the presence of PANI was also discussed. The incorporation of PANI enhances the value of glass transition temperature and thermal stabilityaccording the weight percentage.Further, the water contact angle studies suggest that the coating of PANI and poly(C-ddm)favours superhydrophobic surface $\left(162^{\circ}\right)$ and good oil-water separation (97.5\%). Superior UV shielding throughout the UVA and UVB region renders excellent UPF rating as $50+$. Data resulted from different studies suggestthat the developed PANI incorporated polybenzoxazine matrices coated cotton fabric could be effectively used in some of the industrial and environmental surface protection applications.

\section{Declarations}

\section{Acknowledgement}

The authors thank the PSG Management, Coimbatore, India for their financial support to carry out the present work.

Conflicts of interest

There are no conflicts to declare".

\section{References}

1. Thubsuang U, Ishida H, Wongkasemjit S, Chaisuwan T (2014) Self-formation of 3D interconnected macroporous carbon xerogels derived from polybenzoxazine by selective solvent during the sol-gel process. J Mater Sci 49:4946-4961. https://doi.org/10.1007/s10853-014-8196-1

2. Caldona EB, De Leon ACC, Thomas PG, et al (2017) Superhydrophobic Rubber-Modified Polybenzoxazine/SiO2 Nanocomposite Coating with Anticorrosion, Anti-Ice, and Superoleophilicity 
Properties. Ind Eng Chem Res 56:1485-1497. https://doi.org/10.1021/acs.iecr.6b04382

3. Devaraju S, Prabunathan P, Selvi M, Alagar M (2013) Low dielectric and low surface free energy flexible linear aliphatic alkoxy core bridged bisphenol cyanate ester based POSS nanocomposites. Front Chem 1:19. https://doi.org/10.3389/fchem.2013.00019

4. Wang CF, Su YC, Kuo SW, et al (2006) Low-surface-free-energy materials based on polybenzoxazines. Angew Chemie - Int Ed 45:2248-2251. https://doi.org/10.1002/anie.200503957

5. Daksa Ejeta D, Wang CF, Kuo SW, et al (2020) Preparation of superhydrophobic and superoleophilic cotton-based material for extremely high flux water-in-oil emulsion separation. Chem Eng J 402:126289. https://doi.org/10.1016/j.cej.2020.126289

6. Samy MM, Mohamed MG, Kuo SW (2020) Pyrene-functionalized tetraphenylethylene polybenzoxazine for dispersing single-walled carbon nanotubes and energy storage. Compos Sci Technol 199:108360. https://doi.org/10.1016/j.compscitech.2020.108360

7. Samy MM, Mohamed MG, Kuo SW (2020) Directly synthesized nitrogen-and-oxygen-doped microporous carbons derived from a bio-derived polybenzoxazine exhibiting high-performance supercapacitance and C02 uptake. Eur Polym J 138:109954. https://doi.org/10.1016/j.eurpolymj.2020.109954

8. Ishida H, Froimowicz P (2017) Advanced and Emerging Polybenzoxazine Science and Technology

9. Baqar M, Agag T, Ishida H, Qutubuddin S (2011) Poly(benzoxazine-co-urethane)s: A new concept for phenolic/urethane copolymers via one-pot method. Polymer (Guildf) 52:307-317. https://doi.org/10.1016/j.polymer.2010.11.052

10. Ishida H, Allen DJ (1996) Mechanical characterization of copolymers based on benzoxazine and epoxy. Polymer (Guildf) 37:4487-4495. https://doi.org/10.1016/0032-3861(96)00303-5

11. Alhwaige AA, Ishida H, Qutubuddin S (2019) Poly(benzoxazine-f-chitosan) films: The role of aldehyde neighboring groups on chemical interaction of benzoxazine precursors with chitosan. Carbohydr Polym 209:122-129. https://doi.org/10.1016/j.carbpol.2019.01.016

12. Zhang K, Liu J, Ishida H (2014) An ultrahigh performance cross-linked polybenzoxazole via thermal conversion from poly(benzoxazine amic acid) based on smart o -benzoxazine chemistry. Macromolecules 47:8674-8681. https://doi.org/10.1021/ma502297m

13. El-Mahdy AFM, Kuo SW (2018) Direct synthesis of poly(benzoxazine imide) from an: Ortho benzoxazine: Its thermal conversion to highly cross-linked polybenzoxazole and blending with poly(4-vinylphenol). Polym Chem 9:1815-1826. https://doi.org/10.1039/c8py00087e

14. Feng Z, Zeng M, Meng D, et al (2020) A novel bio-based benzoxazine resin with outstanding thermal and superhigh-frequency dielectric properties. J Mater Sci Mater Electron 31:4364-4376. https://doi.org/10.1007/s10854-020-02995-7

15. Dinesh Kumar G, Prabunathan P, Manoj M, et al (2020) Fluorine Free Bio-Based Polybenzoxazine Coated Substrates for Oil-Water Separation and Anti-lcing Applications. J Polym Environ 28:24442456. https://doi.org/10.1007/s10924-020-01782-z 
16. Yang R, Han M, Hao B, Zhang K (2020) Biobased high-performance tri-furan functional bisbenzoxazine resin derived from renewable guaiacol, furfural and furfurylamine. Eur Polym $\mathrm{J}$ 131:109706. https://doi.org/10.1016/j.eurpolymj.2020.109706

17. Zhan Z, Yan H, Wang H, et al (2020) Novel full bio-based phloroglucinol benzoxazine resin: Synthesis, curing reaction and thermal stability. Polymer (Guildf) 200:122534. https://doi.org/10.1016/j.polymer.2020.122534

18. Barboza LGA, Cunha SC, Monteiro C, et al (2020) Bisphenol A and its analogs in muscle and liver of fish from the North East Atlantic Ocean in relation to microplastic contamination. Exposure and risk to human consumers. J Hazard Mater 393:122419. https://doi.org/10.1016/j.jhazmat.2020.122419

19. Elersek T, Notersberg T, Kovačič A, et al (2020) The effects of bisphenol A, F and their mixture on algal and cyanobacterial growth: from additivity to antagonism. Environ Sci Pollut Res 1-10. https://doi.org/10.1007/s11356-020-10329-7

20. Rezg R, Abot A, Mornagui B, Knauf C (2019) Bisphenol S exposure affects gene expression related to intestinal glucose absorption and glucose metabolism in mice. Environ Sci Pollut Res 26:36363642. https://doi.org/10.1007/s11356-018-3823-z

21. Wang Y, Rui M, Nie Y, Lu G (2018) Influence of gastrointestinal tract on metabolism of bisphenol A as determined by in vitro simulated system. J Hazard Mater 355:111-118. https://doi.org/10.1016/j.jhazmat.2018.05.011

22. Sha XL, Yuan L, Liang G, Gu A (2020) Preparation of high performance bio-based benzoxazine resin through a green solvent-free strategy for shape memory application. Polymer (Guildf) 202:122673. https://doi.org/10.1016/j.polymer.2020.122673

23. Wang Z, Yao S, Song K, et al (2020) A bio-based benzoxazine surfactant from amino acids. Green Chem 22:3481-3488. https://doi.org/10.1039/d0gc00218f

24. Feng Z, Zeng M, Meng D, et al (2020) A novel bio-based benzoxazine resin with outstanding thermal and superhigh-frequency dielectric properties. J Mater Sci Mater Electron 31:4364-4376. https://doi.org/10.1007/s10854-020-02995-7

25. Manoj M, Kumaravel A, Mangalam R, et al (2020) Exploration of high corrosion resistance property of less hazardous pyrazolidine-based benzoxazines in comparison with bisphenol-F derivatives. $\mathrm{J}$ Coatings Technol Res. https://doi.org/10.1007/s11998-019-00312-4

26. Manickam M, Pichaimani P, Arumugam H, Muthukaruppan A (2019) Synthesis of Nontoxic Pyrazolidine-Based Benzoxazine-Coated Cotton Fabric for Oil-Water Separation. Ind Eng Chem Res 58:21419-21430. https://doi.org/10.1021/acs.iecr.9b03440

27. Li S, Zou T, Feng L, et al (2013) Preparation and properties of cardanol-based polybenzoxazine/SiO2 hybrids by sol-gel technique. J Appl Polym Sci 128:4164-4171. https://doi.org/10.1002/app.38607

28. Zhang C, Zhang Y, Zhou Q, et al (2014) Processability and mechanical properties of bisbenzoxazine modified by the cardanol-based aromatic diamine benzoxazine. J Polym Eng 34:561-568. https://doi.org/10.1515/polyeng-2014-0018 
29. Patil DM, Phalak GA, Mhaske ST (2017) Enhancement of anti-corrosive performances of cardanol based amine functional benzoxazine resin by copolymerizing with epoxy resins. Prog Org Coatings 105:18-28. https://doi.org/10.1016/j.porgcoat.2016.10.027

30. Li SF, Huang WD (2011) Synthesis of new benzoxazine from cardanol-furfural resin and the properties of the corresponding polymer. Adv Mater Res 236-238:317-320. https://doi.org/10.4028/www.scientific.net/AMR.236-238.317

31. Prabunathan P, Elumalai P, Dinesh Kumar G, et al (2020) Antiwetting and low-surface-energy behavior of cardanol-based polybenzoxazine-coated cotton fabrics for oil-water separation. J Coatings Technol Res 1-15. https://doi.org/10.1007/s11998-020-00365-w

32. Calò E, Maffezzoli A, Mele G, et al (2007) Synthesis of a novel cardanol-based benzoxazine monomer and environmentally sustainable production of polymers and bio-composites. Green Chem 9:754-759. https://doi.org/10.1039/b617180j

33. Shukla S, Yadav N, Lochab B (2017) Cardanol-Based Benzoxazines and Their Applications. In: Advanced and Emerging Polybenzoxazine Science and Technology. pp 451-472

34. Trejo-Machin A, Puchot L, Verge P (2020) A cardanol-based polybenzoxazine vitrimer: Recycling, reshaping and reversible adhesion. Polym Chem 11:7026-7034. https://doi.org/10.1039/d0py01239d

35. Sharma P, Dutta P, Nebhani L (2020) Integration of silica with benzoxazine to improve particle dispersion and thermal performance of composites. Colloids Surfaces A Physicochem Eng Asp 592:124515. https://doi.org/10.1016/j.colsurfa.2020.124515

36. Rao BS, Palanisamy A (2012) A new thermo set system based on cardanol benzoxazine and hydroxy benzoxazoline with lower cure temperature. Prog Org Coatings 74:427-434. https://doi.org/10.1016/j.porgcoat.2012.01.006

37. Wang Y, Niu X, Xing X, et al (2017) Curing behaviour and properties of a novel benzoxazine resin via catalysis of 2-phenyl-1,3,2-benzodioxaborole. React Funct Polym 117:60-69. https://doi.org/10.1016/j.reactfunctpolym.2017.06.004

38. Sun J, Wei W, Xu Y, et al (2015) A curing system of benzoxazine with amine: Reactivity, reaction mechanism and material properties. RSC Adv 5:19048-19057. https://doi.org/10.1039/c4ra16582a

39. Lin SC, Wu CS, Yeh JM, Liu YL (2014) Reaction mechanism and synergistic anticorrosion property of reactive blends of maleimide-containing benzoxazine and amine-capped aniline trimer. Polym Chem 5:4235-4244. https://doi.org/10.1039/c4py00274a

40. Rao BS, Palanisamy A (2013) Synthesis of bio based low temperature curable liquid epoxy, benzoxazine monomer system from cardanol: Thermal and viscoelastic properties. Eur Polym $\mathrm{J}$ 49:2365-2376. https://doi.org/10.1016/j.eurpolymj.2013.05.029

41. Arumugam H, Krishnan S, Chavali M, Muthukaruppan A (2018) Cardanol based benzoxazine blends and bio-silica reinforced composites: Thermal and dielectric properties. New J Chem 42:4067-4080. https://doi.org/10.1039/c7nj04506a 
42. Prabunathan $P$, Vasanthakumar $A$, Manoj $M$, et al (2020) Polypyrrole inter-layered low temperature curing benzoxazine matrices with enhanced thermal and dielectric properties. J Polym Res 27:1-14. https://doi.org/10.1007/s10965-020-2022-z

43. Zhang L, Mao J, Wang S, et al (2017) Meta-phenylenediamine formaldehyde oligomer: A new accelerator for benzoxazine resin. React Funct Polym 121:51-57.

https://doi.org/10.1016/j.reactfunctpolym.2017.10.020

44. Prabunathan P, Sethuraman K, Alagar M (2014) MnO2-doped, polyaniline-grafted rice husk ash nanocomposites and their electrochemical capacitor applications. RSC Adv 4:47726-47734. https://doi.org/10.1039/c4ra04633a

45. Shukla S, Lochab B (2016) Role of higher aromatic content in modulating properties of cardanol based benzoxazines. Polymer (Guildf) 99:684-694. https://doi.org/10.1016/j.polymer.2016.07.074

46. Li S, Zou T, Feng L, et al (2013) Preparation and properties of cardanol-based polybenzoxazine/SiO2 hybrids by sol-gel technique. J Appl Polym Sci 128:4164-4171. https://doi.org/10.1002/app.38607

47. Zong J, Ran Q (2019) Ring Opening Reaction of 3,4-Dihydro-2H-1,3-Benzoxazine with Amines at Room Temperature. ChemistrySelect 4:6687-6696. https://doi.org/10.1002/slct.201901447

48. Demir KD, Kiskan B, Latthe SS, et al (2013) Thermally curable fluorinated main chain benzoxazine polyethers via Ullmann coupling. Polym Chem 4:2106-2114. https://doi.org/10.1039/c2py21029k

49. Jang J, Yang H (2000) Effect of surface treatment on the performance improvement of carbon fiber/polybenzoxazine composites. J Mater Sci 35:2297-2303.

https://doi.org/10.1023/A:1004791313979

50. Wu X, Lu C, Xu H, et al (2014) Biotemplate synthesis of polyaniline@cellulose nanowhiskers/natural rubber nanocomposites with 3D hierarchical multiscale structure and improved electrical conductivity. ACS Appl Mater Interfaces 6:21078-21085. https://doi.org/10.1021/am505924z

51. Kumar V, Yokozeki T, Goto T, Takahashi T (2015) Mechanical and electrical properties of PANI-based conductive thermosetting composites. J Reinf Plast Compos 34:1298-1305.

https://doi.org/10.1177/0731684415588551

52. Oyharçabal M, Olinga T, Foulc MP, Vigneras V (2012) Polyaniline/clay as nanostructured conductive filler for electrically conductive epoxy composites. Influence of filler morphology, chemical nature of reagents, and curing conditions on composite conductivity. Synth Met 162:555-562. https://doi.org/10.1016/j.synthmet.2012.02.011

53. Zhang X, He Q, Gu H, et al (2013) Flame-retardant electrical conductive nanopolymers based on bisphenol F epoxy resin reinforced with nano polyanilines. ACS Appl Mater Interfaces 5:898-910. https://doi.org/10.1021/am302563w

54. Rao BS, Palanisamy A (2011) Monofunctional benzoxazine from cardanol for bio-composite applications. React Funct Polym 71:148-154. https://doi.org/10.1016/j.reactfunctpolym.2010.11.025

55. Su YC, Chang FC (2003) Synthesis and characterization of fluorinated polybenzoxazine material with low dielectric constant. Polymer (Guildf) 44:7989-7996. 
https://doi.org/10.1016/j.polymer.2003.10.026

56. Aly KI, Mahdy A, Hegazy MA, et al (2020) Corrosion Resistance of Mild Steel Coated with Phthalimide-Functionalized Polybenzoxazines. Coatings 10:1114. https://doi.org/10.3390/coatings10111114

57. Mohamed MG, Kuo SW, Mahdy A, et al (2020) Bisbenzylidene cyclopentanone and cyclohexanonefunctionalized polybenzoxazine nanocomposites: Synthesis, characterization, and use for corrosion protection on mild steel. Mater Today Commun 25:101418. https://doi.org/10.1016/j.mtcomm.2020.101418

58. Thennarasu P, Prabunathan P, Senthilkumar M (2018) Development of biomass-derived functionalized activated carbon-coated and polyaniline-grafted cotton fabric with enhanced ultraviolet resistance. J Ind Text 47:1609-1625. https://doi.org/10.1177/1528083717702008

59. Li C, Shu S, Chen R, et al (2013) Functionalization of electrospun nanofibers of natural cotton cellulose by cerium dioxide nanoparticles for ultraviolet protection. J Appl Polym Sci 130:15241529. https://doi.org/10.1002/app.39264

60. Becheri A, Dürr M, Lo Nostro P, Baglioni P (2008) Synthesis and characterization of zinc oxide nanoparticles: Application to textiles as UV-absorbers. J Nanoparticle Res 10:679-689. https://doi.org/10.1007/s11051-007-9318-3

61. Tang X, Tian M, Qu L, et al (2015) Functionalization of cotton fabric with graphene oxide nanosheet and polyaniline for conductive and UV blocking properties. Synth Met 202:82-88. https://doi.org/10.1016/j.synthmet.2015.01.017

62. Zhang W, Lu X, Xin Z, Zhou C (2016) Development of a superhydrophobic polybenzoxazine surface with self-cleaning and reversible water adhesion properties. RSC Adv 6:106054-106063. https://doi.org/10.1039/C6RA22524A

63. Jeevahan J, Chandrasekaran M, Britto Joseph G, et al (2018) Superhydrophobic surfaces: a review on fundamentals, applications, and challenges. J. Coatings Technol. Res. 15:231-250

\section{Figures}




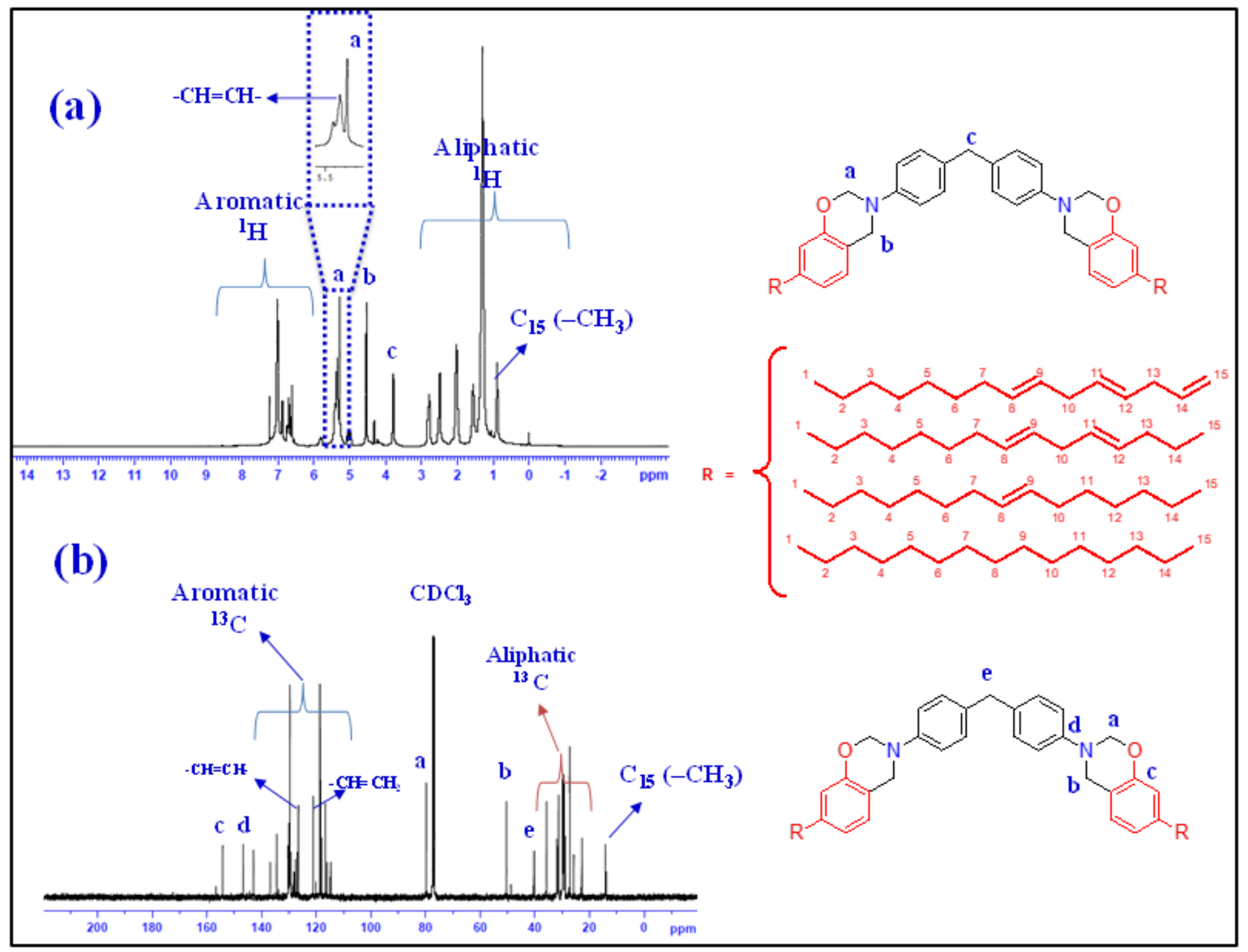

Figure 1

(a) 1H-NMR and (b) 13C-NMR Spectra of C-ddm monomer. 


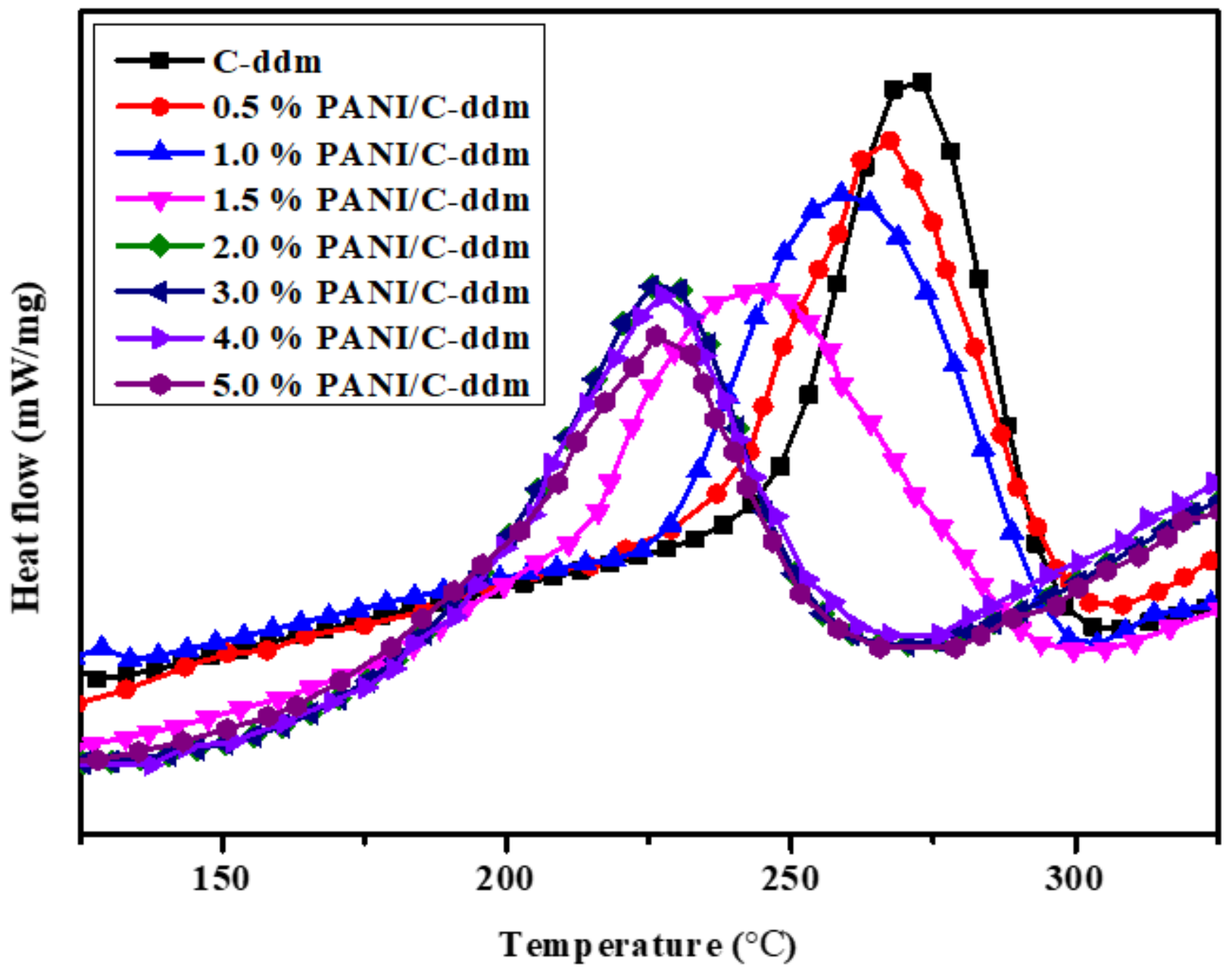

Figure 2

DSC thermogram of C-ddm, $1 \%$ and $2 \%$ PANI/C-ddm. 


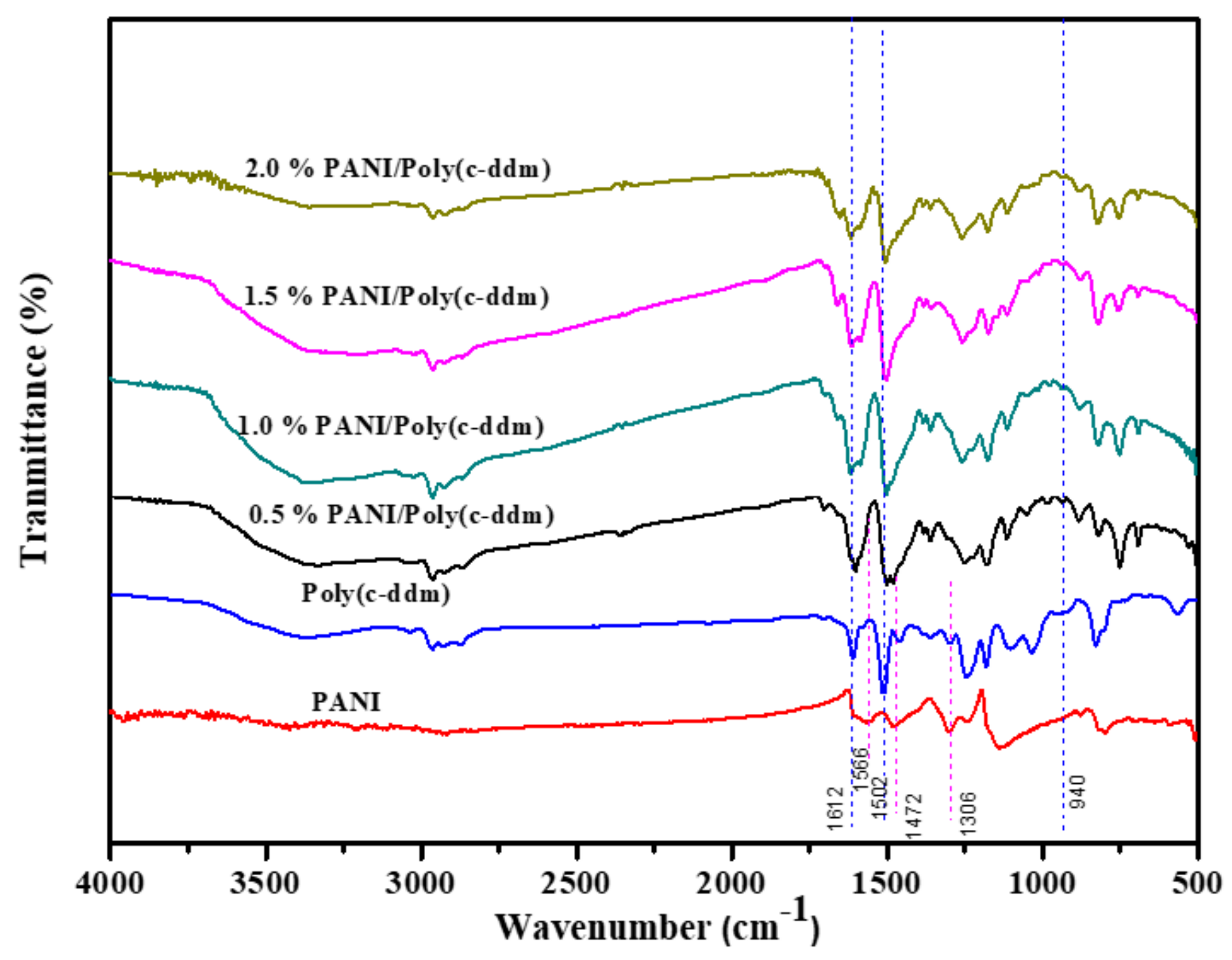

Figure 3

FTIR Spectra of PANI/Poly(C-ddm). 


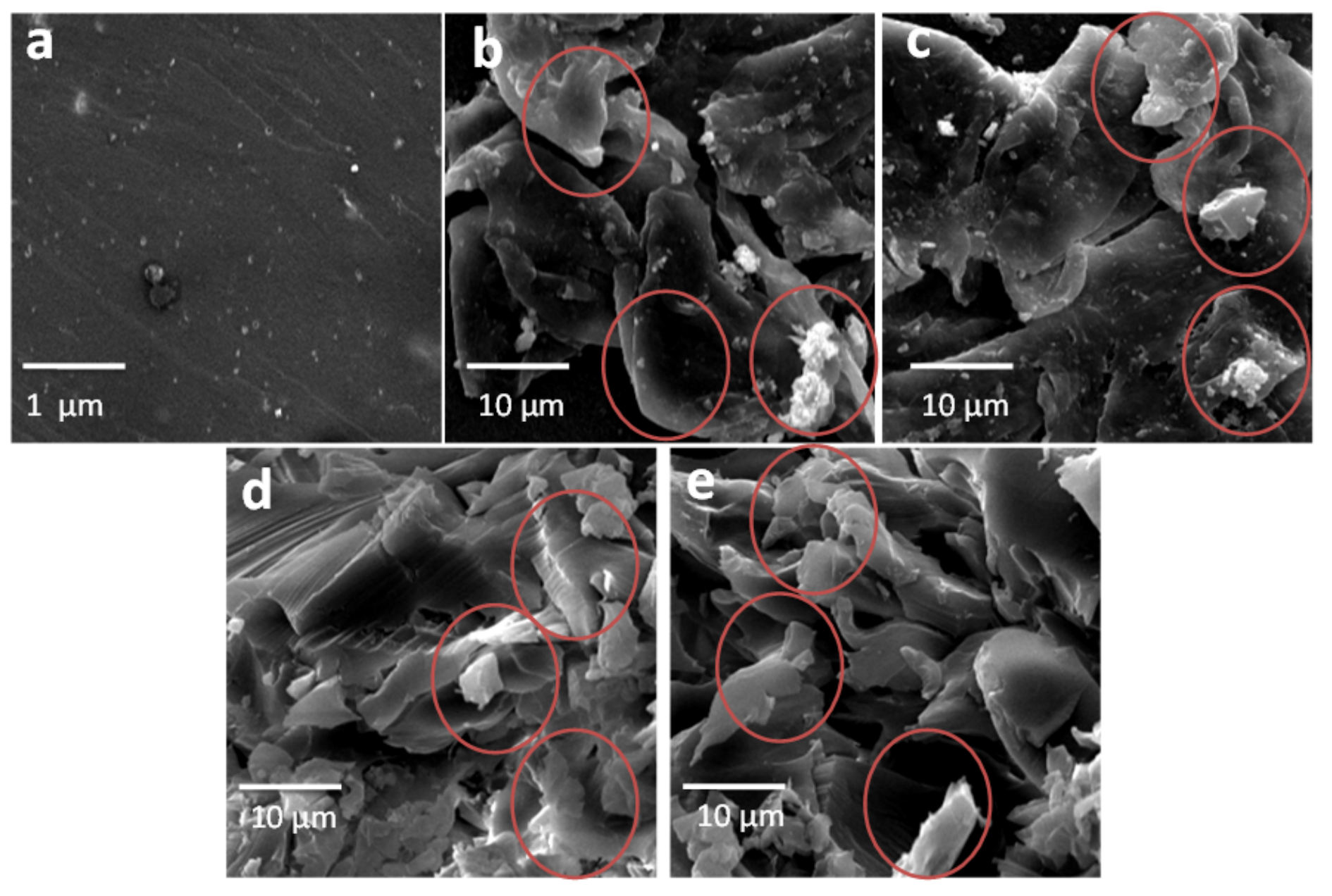

Figure 4

FE-SEM images of a) neat poly (C-ddm) and b) $0.5 \%$ c) $1.0 \%$ d) $1.5 \%$ and e) $2.0 \%$ PANI/Poly(C-ddm). 


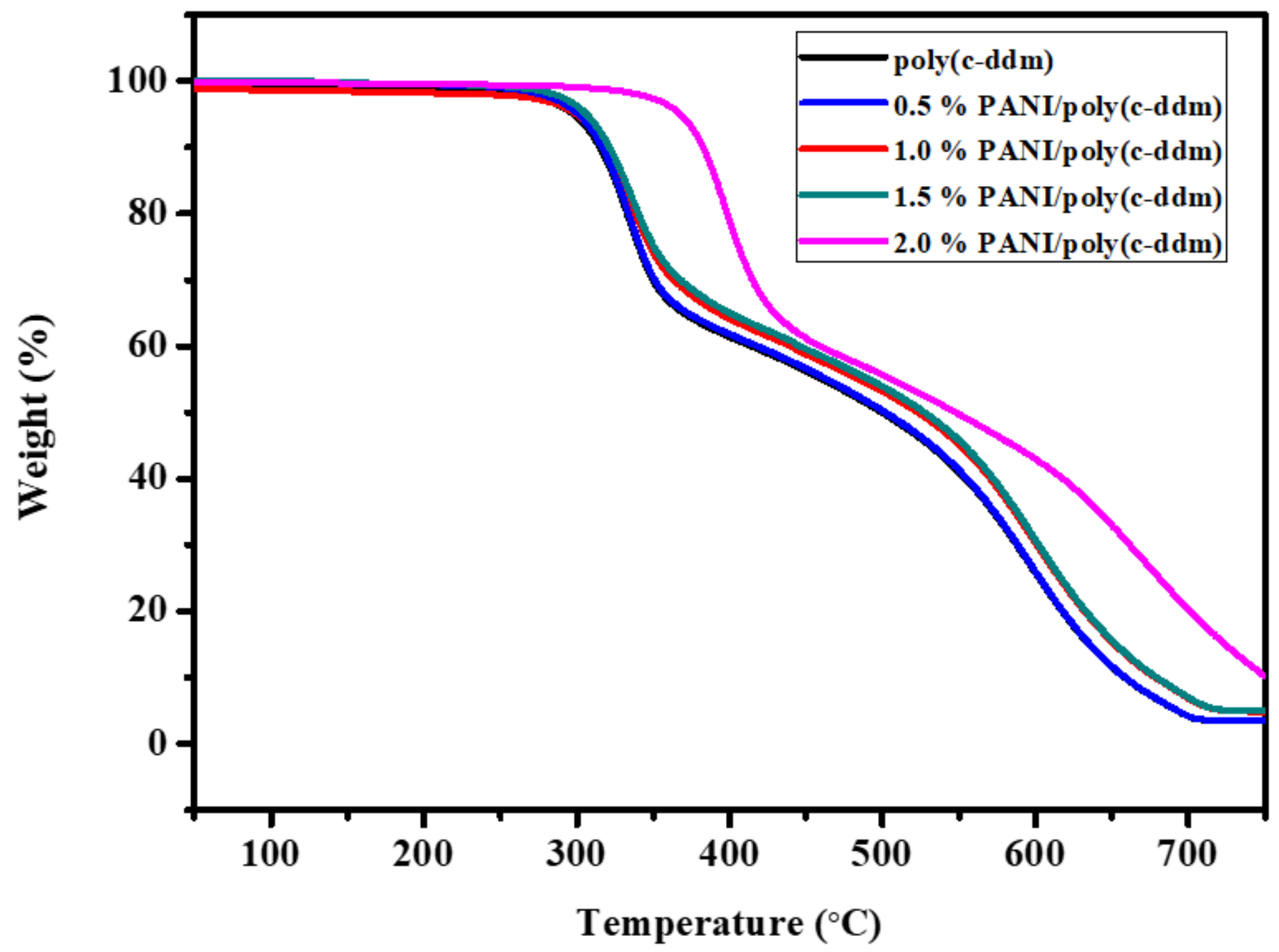

Figure 5

TGA Profile of Neat poly(C-ddm) and PANI/Poly(C-ddm). 


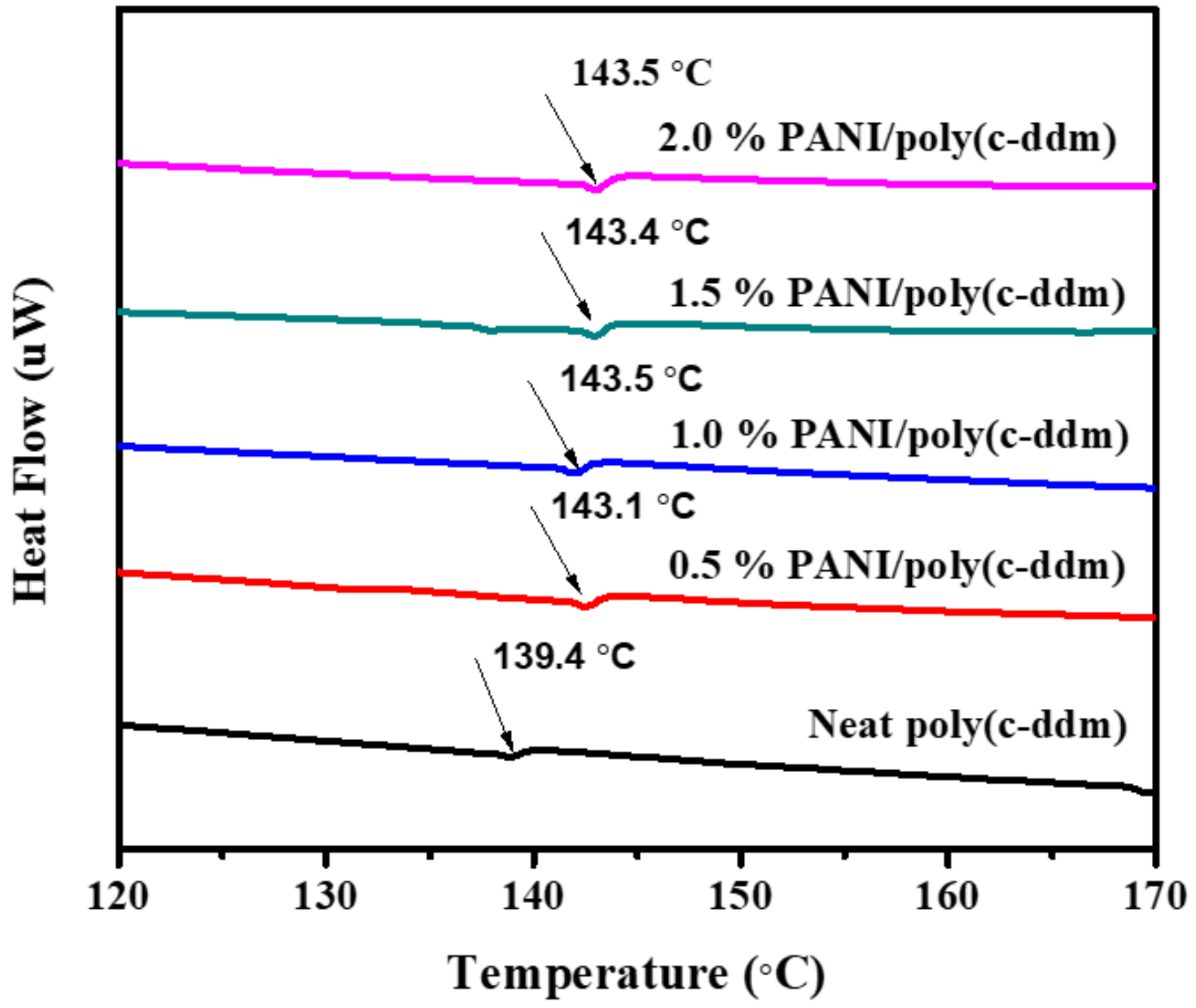

Figure 6

DSC thermogram of neat poly(C-ddm) and PANI/Poly(C-ddm). 


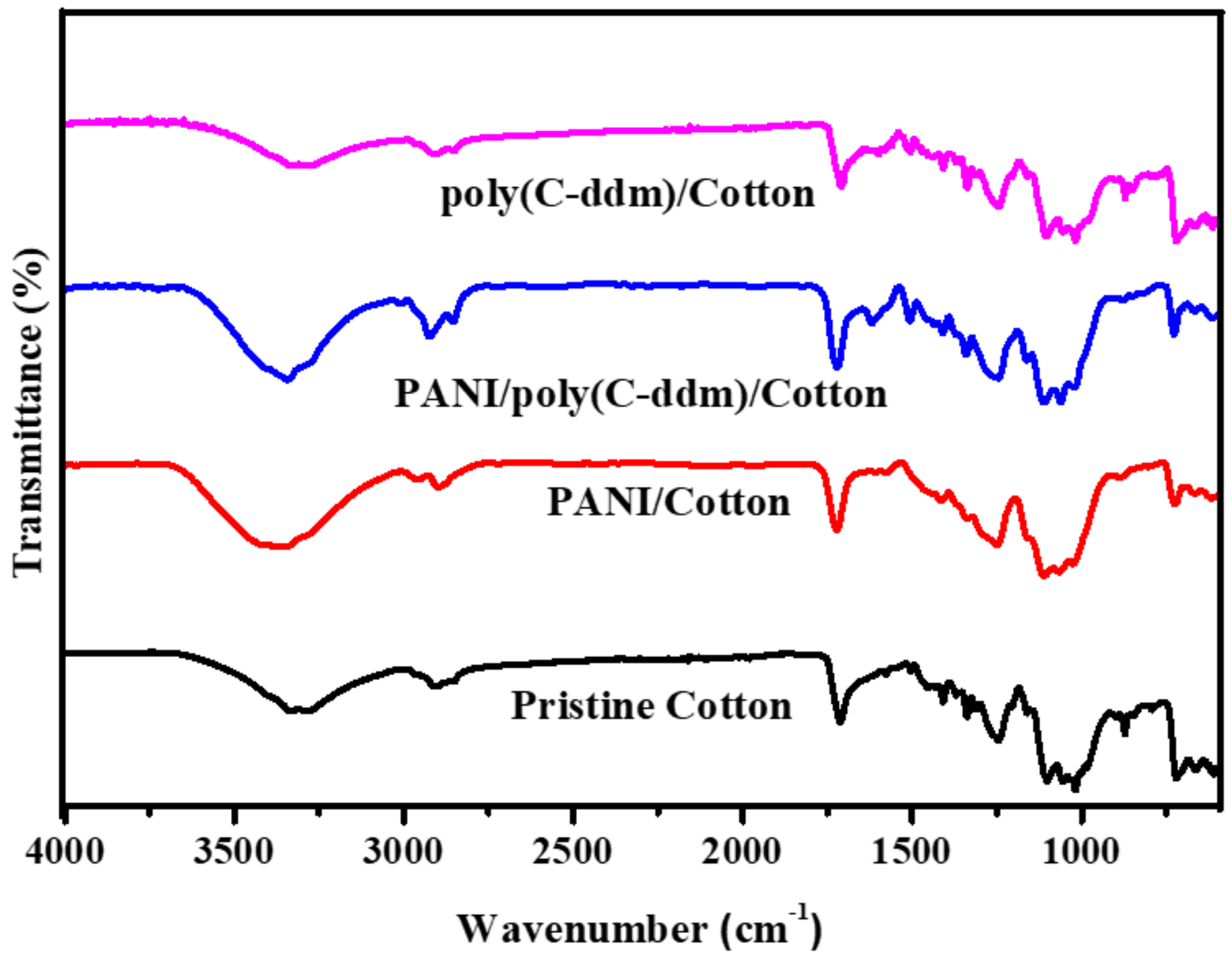

Figure 7

FTIR Spectra of pristine cotton, poly(C-ddm)/cotton. PANI/cotton and PANI/Poly(C-ddm)/cotton fabrics. 


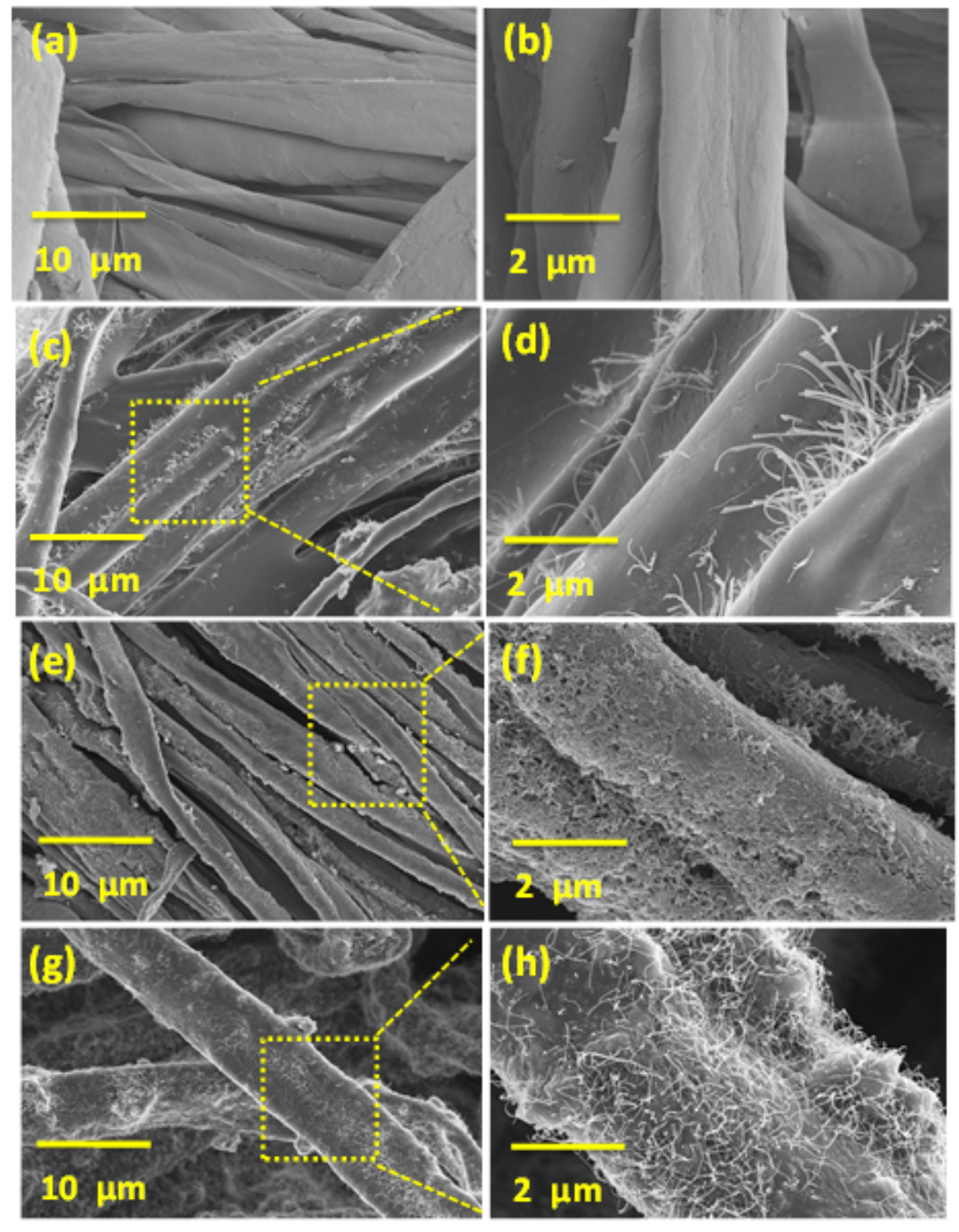

Figure 8

FESEM spectra of pristine cotton, poly(C-ddm)/cotton. PANI/cotton and PANI/Poly(C-ddm)/cotton fabrics. 


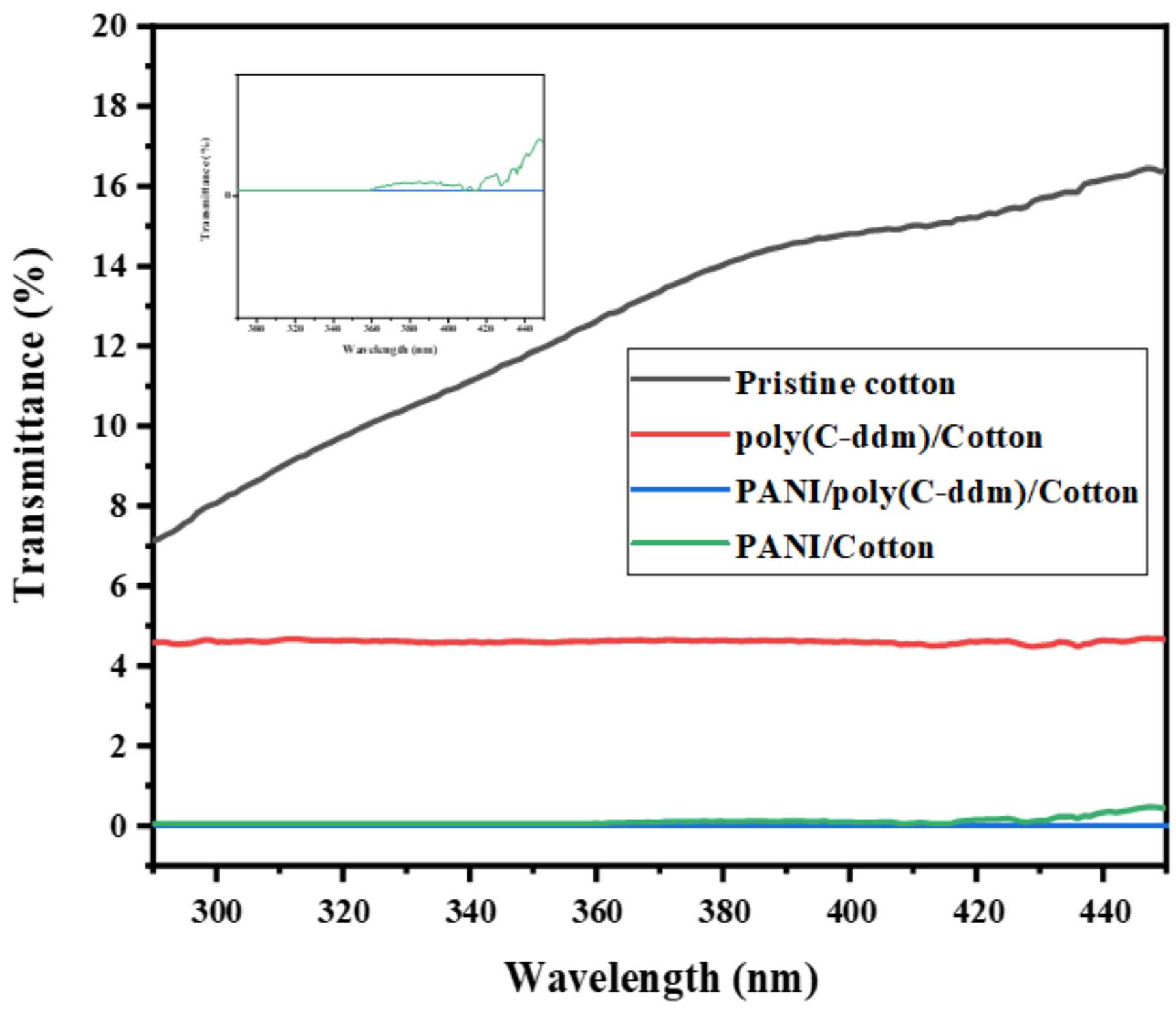

Figure 9

UV shielding behavior of pristine cotton, poly(C-ddm)/cotton, PANI/cotton and PANI/poly(C-ddm)/cotton fabrics. 
(a)

(b)

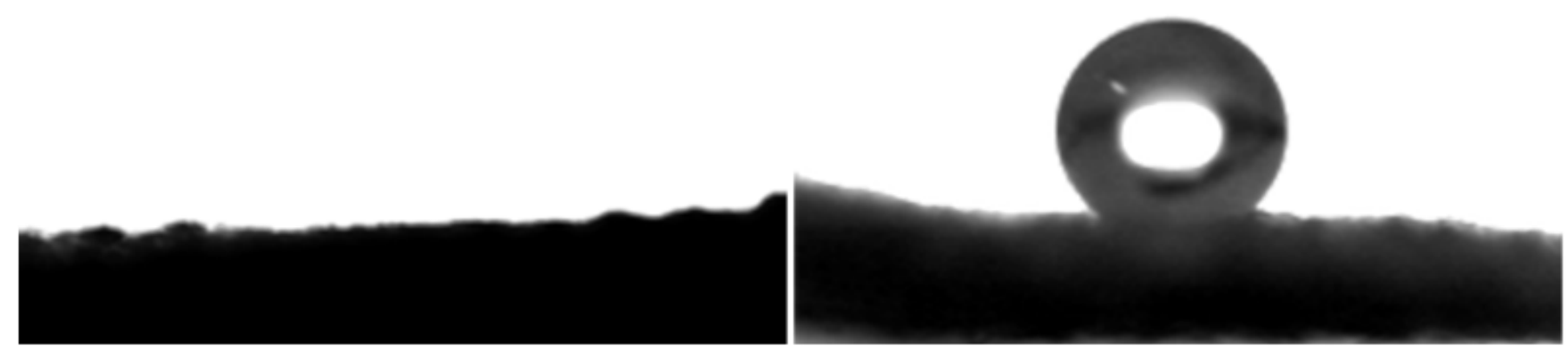

(c) $\quad$ (d)

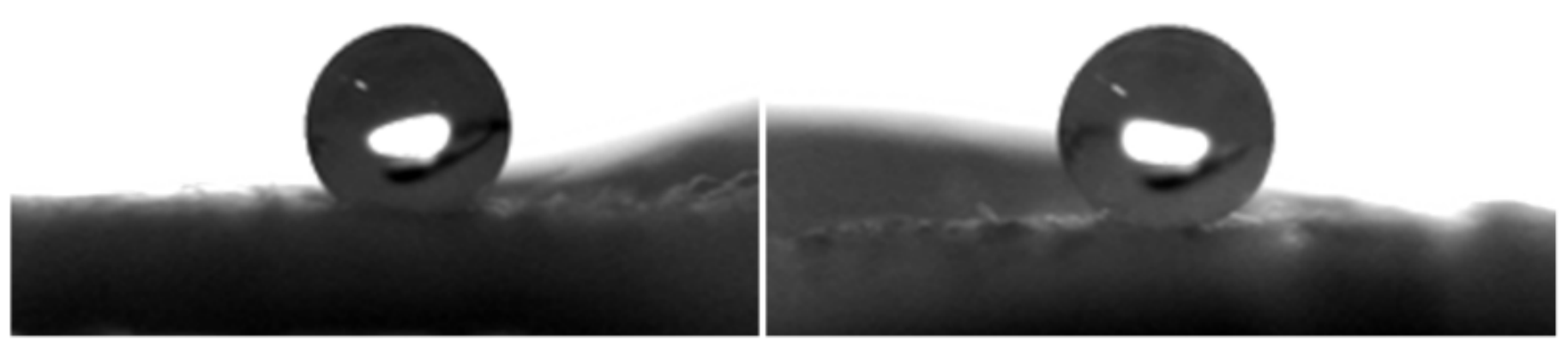

Figure 10

Contact angle images of (a) pristine cotton, (b)poly(C-ddm)/cotton, (c) PANI/cotton and (d) PANI/poly(C$\mathrm{ddm}) /$ cotton fabric. 

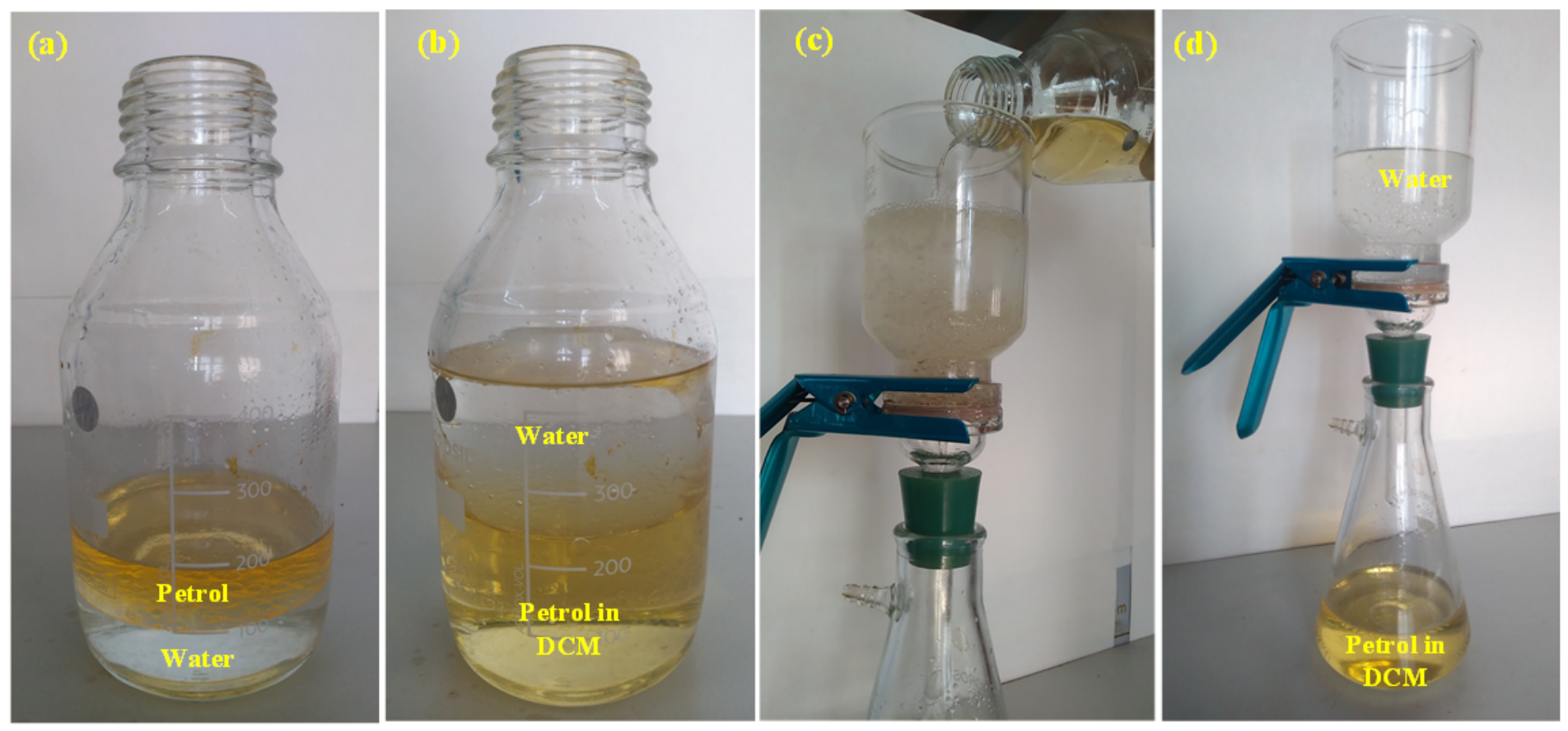

\section{Figure 11}

(a) petrol-water mixture, (b) petrol-water mixture in DCM, (c) separation process of petrol-water mixture in DCM (d) Separated petrol in DCM and water layer. 

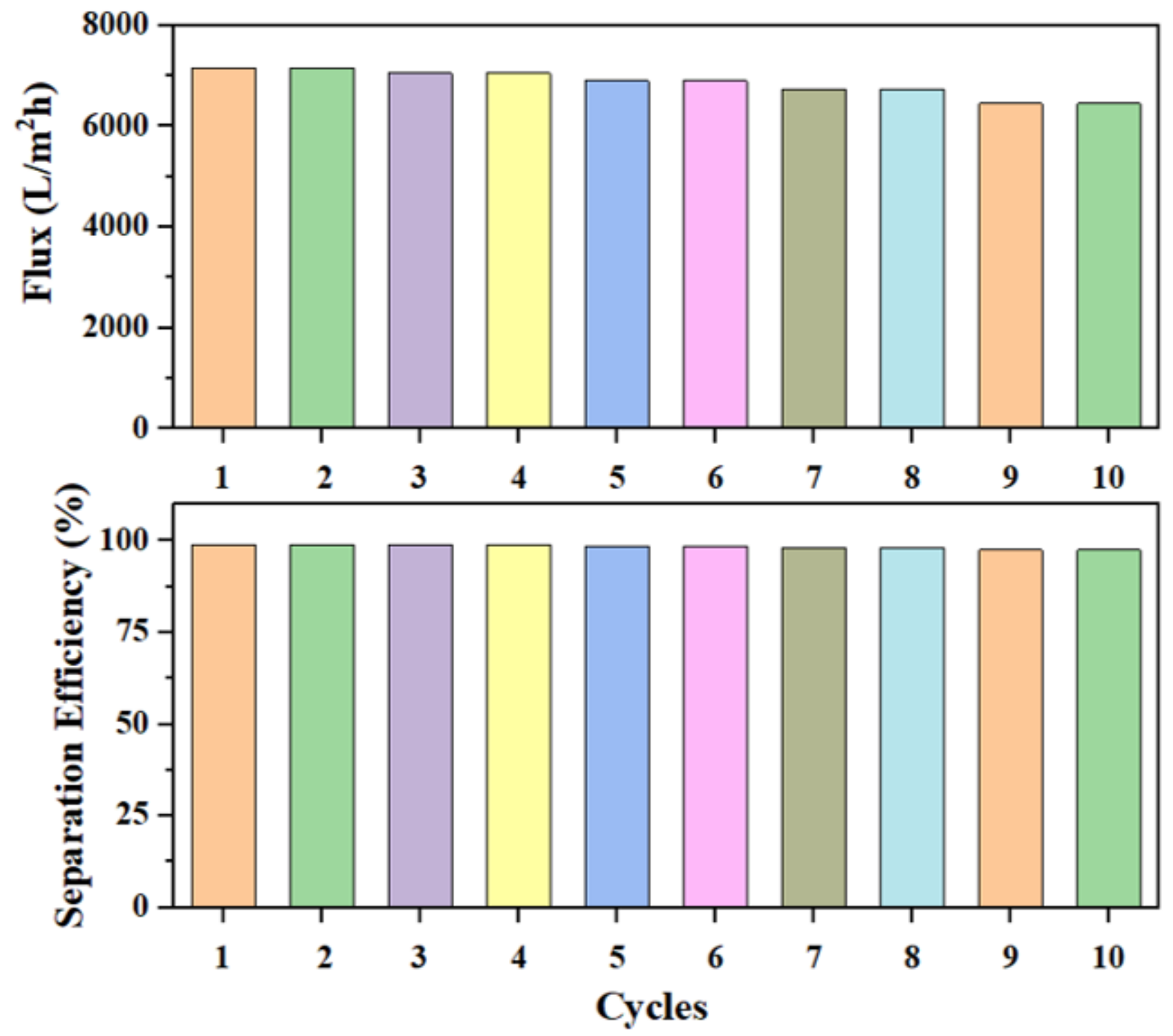

Figure 12

(a) Petrol/water separation efficiency (\%) and (b) flux (L/m2h) of PANI/poly(C-ddm)/cotton fabricat different cycles.

\section{Supplementary Files}

This is a list of supplementary files associated with this preprint. Click to download.

- SupportingInformation.docx

- Scheme1.png

- Scheme2.png 